\title{
In-situ holographic elastic moduli measurements from boreholes
}

\author{
Douglas R. Schmitt*, Catherine Smither $\neq$, and Thomas J. Ahrensł
}

\section{ABSTRACT}

We have developed a unique technique employing optical holography to measure the static Young's modulus $(E)$ from a borehole. In the experiment, a known point force induces micron scale displacements on the borehole wall which are recorded by a double-exposure hologram. Raw data consist of dark fringes superimposed on the three-dimensional image whose pattern is modeled to find $E$ directly. In the laboratory, the holographic technique determined $E$ on rock and metal samples to an uncertainty better than 10 percent. For example, double exposure holograms of a saw-cut sample of dolomitic marlstone gave an $E$ of $16.8 \pm 2.8 \mathrm{GPa}$ in agreement with $17.2 \pm 2.0 \mathrm{GPa}$ predicted by published density-modulus relationships. Field tests of a holographic tool in a horizontal mine pillar borehole gave in-situ Es which range from 26.9 to $36.0 \mathrm{GPa}$. Although these data could be interpreted as localized elastic heterogeneity within the rock mass, elastic anisotropy of the rock is a possible explanation for this variation.

\section{INTRODUCTION}

Knowledge of the state of stress in the Earth is an essential component of the solution to many geotechnical and geophysical problems. Stresses within the Earth affect underground repository design and safe mine construction (e.g., Stephansson, 1986). Lithospheric stresses constrain the tectonic driving forces (e.g., Richardson et al., 1979). Using hydrofracture to stimulate petroleum and geothermal energy recovery requires knowledge of the orientation and magnitude of the principal stresses. Moreover, in-situ stress controls seismic anisotropy of rock due to preferential orientation of microfracture openings (Thomsen, 1986; Crampin, 1978; Nur, 1971; Stesky, 1985).

The primary objective of our research is to determine from a borehole the state of stress in the Earth. We previously described an experimental technique to obtain the complete in-situ stress tensor by recording stress-relief displacements, which are induced by drilling a small hole perpendiculary into the wall of a borehole, with double-exposure holography (Bass et al., 1986; Smither et al., 1988). However, analysis of these stress-relief displacements requires knowledge of the in-situ elastic moduli. We have adapted our borehole holographic tool for the determination of the in-situ elastic (Young's) modulus, $E$. In this application, a displacement field is induced on the borehole wall by applying a known point force normal to the borehole wall rock. The present borehole instrument is thus capable of conducting the two complementary determinations of stress-relief displacements and elastic moduli, both of which are necessary for stress measurement.

The value of performing both experiments with the holographic technique is further reinforced by the fact that induced normal force and stress-relief displacements and strains are similar. The double-exposure holograms are capable of resolving displacements as small as 0.1 microns or approximately one-sixth the wavelength of the laser radiation used. Calibration of the optics module with known translational displacements has been previously discussed (Bass et al., 1986). Maximum displacement magnitudes for both experiments are $<10$ microns and strains encountered are approximately $100 \mathrm{mi}-$ crostrains measured over a $10 \mathrm{~cm}$ square region. In contrast, conventional in-situ static elastic modulus testing methodscompression tests, plate-bearing tests, flat jack tests, dilatometer tests, and the N-X borehole jack tests (Bieniawski, 1978; Jaeger, 1979) -measure the rock elastic moduli on varying length scales, force levels, and strain magnitudes. For example, the N-X borehole jack applies up to $700 \mathrm{kN}$ of force via $20.3 \mathrm{~cm}$ long platens to a $7.62 \mathrm{~cm}$ diameter borehole, producing typical displacements of $0.2 \mathrm{~mm}$ (Meyer and McVey, 1974) with strain magnitudes near 1 mstrain. In the plate-bearing experiment, forces of up to $11.8 \mathrm{MN}$ are applied to areas on the order of $1 \mathrm{~m}^{2}$ which induce displacements up to $2.5 \mathrm{~mm}$ and strains of 1 mstrain (Jaeger, 1979).

Presented at the 56th Annual International Meeting, Society of Exploration Geophysicists. Manuscript received by the Editor October 2, 1987; revised manuscript received September 12, 1988.

${ }^{*}$ Formerly Seismological Laboratory, California Institute of Technology; presently Institute of Earth and Planetary Physics, Department of Physics, University of Alberta, Edmonton, Alta., Canada T6G 2J1.

${ }_{\dagger}^{\dagger}$ Seismological Laboratory, California Institute of Technology, Pasadena, CA 91125.

O 1989 Society of Exploration Geophysicists. All rights reserved. 
In-situ static Young's moduli are a function of experimental scale and discontinuity density, i.e., the larger the volume of rock deformed during a measurement, the higher the probability that a discontinuity within the rock will be affected, resulting in a higher compressibility (Bieniawski and Van Heerden, 1975). The holographic elastic modulus test supplies small-scale values ( $<11$ volume) of $E$ and would benefit other stress measurement techniques such as the the C.S.I.R doorstopper cell, the triaxial strain cell, the direct strain gauge technique (McGarr and Gay, 1978), and the borehole slotter stressmeter (Bock et al., 1984).

Although normal forces have been used previously to measure in-situ elastic moduli, the present use with doubleexposure holography is new: The plate-bearing method of determining elastic moduli in rock (Jaeger and Cook. 1979) shares an identical theoretical basis with the present method but relies upon dial gauges for measurement of displacements. Our raw data consist of a series of dark interference fringes superimposed upon the reconstructed image of the borehole wall. The density and pattern of the fringes depend uniquely on the magnitudes and directions of the induced displacement fields, which in turn are dependent on the rock elastic moduli.

The theory behind the holographic elastic moduli measurements and the data analysis are outlined below. The results of laboratory normal force experiments on brass and aluminum alloys, as well as on a sample of dolomitic marlstone (oil shale), are discussed. Results of recent deployment of the holographic tool in a borehole in a mine pillar of dolomitic marlstone are also presented.

\section{DOUBLE-EXPOSURE HOLOGRAPHY}

Double-exposure holography (Vest, 1979) is an optical interferometric technique to record a three-dimensional (3-D) displacement field which occurs between two holographic exposures of a single emulsion. The off-axis holograms are created with monochromatic laser radiation (Figure 1). A double- exposure hologram is, in effect, two off-axis holograms on the same film. It is produced by taking a holographic exposure of an object, then translating or deforming the surface of the object, and finally taking a second holographic exposure. In our experiments, a portion of the borehole wall surface $(\sim 10$ $\left.\mathrm{cm}^{2}\right)$ is the object; the displacements induced by normal force application (Figure 1) occur between exposures of the film. The result is a 3-D image of the borehole wall with a superimposed fringe pattern (see Figure 10).

An optical hologram is a high line density diffraction pattern ( $>1000$ lines per centimeter) produced by the interference of a reference beam and light nonspecularly reflected from the object, referred to as an object beam, within the emulsion of the holographic film (Figure 1). Reconstruction of the hologram occurs when a replica of the reference beam is passed through the hologram to diffract and recreate the object beam. In this way both the amplitude and the phase of the original object wave field are reproduced, resulting in a 3-D virtual image. We pass an unexpanded laser beam through the hologram to form a two-dimensional (2-D) real image of the object; our raw data are photographs of these images (Schmitt, 1987). From a double-exposure hologram, two slightly different object wave fields are reconstructed, which interfere to produce the displacement-dependent fringe patterns.

A fringe on a double-exposure holographic image occurs when ray (S-P-H) from the first exposure (Figure 2) and ray $\left(\mathrm{S}-\mathrm{P}^{\prime}-\mathrm{H}\right)$ from the second exposure destructively interfere. In addition to the displacement ( $\mathrm{L}$ ) between exposures, fringe existence depends upon the relative positions of the object beam source $(S)$, the displaced object locations $\left(P\right.$ and $\left.P^{\prime}\right)$, and the point on the holographic emulsion $(H)$ from which the image is viewed and represented by the position vectors $\mathbf{R}, \mathbf{r}_{1}$, and $\mathbf{r}_{3}$. The wave vectors $\mathbf{k}_{1}, \mathbf{k}_{2}, \mathbf{k}_{\mathbf{3}}$, and $\mathbf{k}_{4}$ have magnitudes of $2 \pi / \lambda$, where $\lambda$ is the wavelength; the projection of a wave vector upon its corresponding position vector yields the phase of the light at the end of the position vector. The phases of the
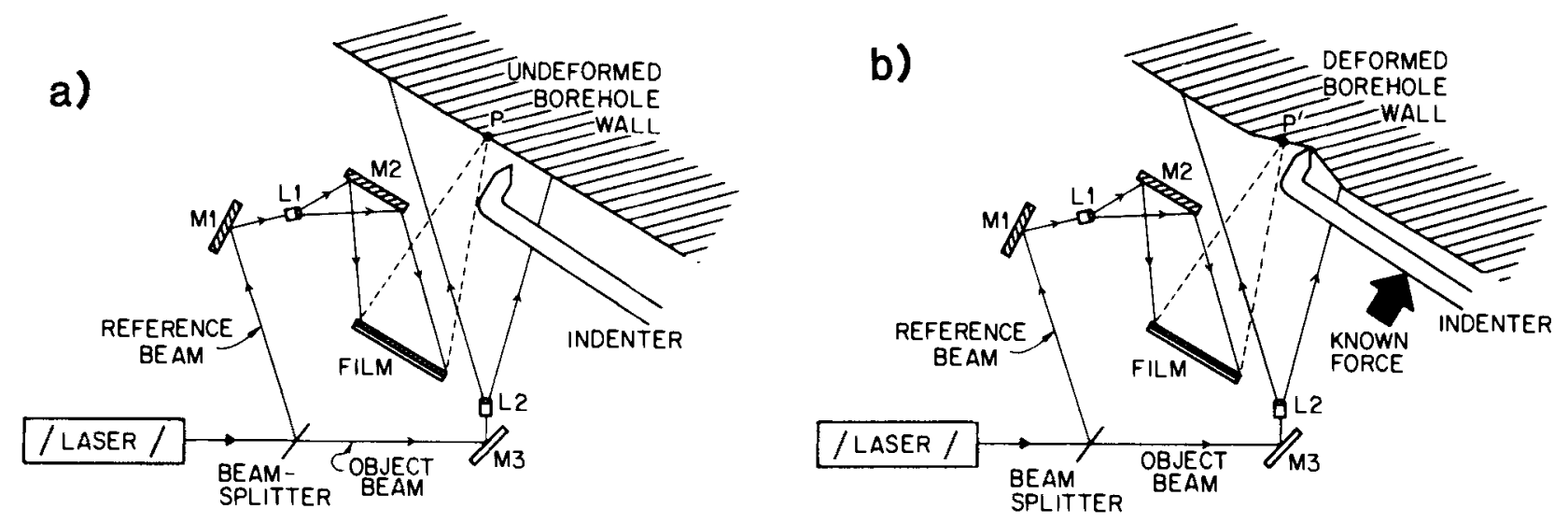

FiG. 1. Method of producing a double-exposure hologram for the normal force elastic modulus measurement experiment. To create an off-axis hologram, monochromatic laser radiation is separated into two paths by a beam splitter. The reference beam is diverted by mirrors M 1 and M2 and expanded by lens L1 to illuminate only the film emulsion. The object beam is diverted by mirror M3 and expanded by lens L2 to illuminate the borehole wall which scatters the light back to the film. The object and reference beams interfere in the emulsion and produce a diffraction pattern which is the hologram. (a) Schematic of elastic moduli experiment during first holographic exposure; $P$ is a point on the borehole wall within the field of view of the hologram. (b) Known force is applied by the steel indenter to the borehole wall and induces a $3-D$ displacement field; $P^{\prime}$ represents the displaced position of $P$. While the displacement field is maintained, the second exposure is taken on the same film. 
light reaching $\mathrm{H}$ after being reflected from $\mathrm{P}$ for the first exposure and $\mathrm{P}^{\prime}$ for the second exposure are given by (Vest, 1979)

$$
\Phi=\mathbf{k}_{1} \cdot \mathbf{r}_{1}+\mathbf{k}_{2} \cdot\left(\mathbf{R}-\mathbf{r}_{1}\right)
$$

and

$$
\Phi^{\prime}=\mathbf{k}_{3} \cdot \mathbf{r}_{3}+\mathbf{k}_{\mathbf{4}} \cdot\left(\mathbf{R}-\mathbf{r}_{3}\right)
$$

The phase difference $\delta=\Phi^{\prime}-\Phi$ between the first and second paths is

$$
\delta=\left(\mathbf{k}_{2}-\mathbf{k}_{1}\right) \cdot\left(\mathbf{r}_{1}-\mathbf{r}_{3}\right)+\Delta \mathbf{k}_{1} \cdot \mathbf{r}_{3}+\Delta \mathbf{k}_{2} \cdot\left(\mathbf{R}-\mathbf{r}_{3}\right),
$$

where $\Delta \mathbf{k}_{1}=\mathbf{k}_{3}-\mathbf{k}_{1}$ and $\Delta \mathbf{k}_{2}=\mathbf{k}_{4}-\mathbf{k}_{2}$. Note the displacement occurring between the exposures in the movement of $P$ to $P^{\prime}$ is given by $L=r_{1}-r_{3}$ (Figure 2) with a magnitude of microns in contrast to the several centimeter magnitudes of the position vectors. As a result, the vectors $\Delta \mathbf{k}_{1}$ and $\Delta \mathbf{k}_{2}$ are nearly perpendicular to the position vectors $\mathbf{r}_{3}$ and $\left(\mathbf{R}-\mathbf{r}_{3}\right)$, respectively, and their projections upon the position vectors vanish to simplify equation (3) to

$$
\delta \cong\left(\mathbf{k}_{2}-\mathbf{k}_{1}\right) \cdot \mathbf{L} .
$$

A dark fringe occurs when light rays from $P$ and $P^{\prime}$ interfere destructively, a condition that is met when $\delta$ corresponds to an odd number of half-wavelengths of laser light. Note that $\delta$ is sensitive to the component of displacement $\mathbf{L}$ parallel to the sensitivity vector $\mathbf{K}=\mathbf{k}_{2}-\mathbf{k}_{1}$.

\section{DATA ANALYSIS AND THEORY OF DISPLACEMENTS}

\section{Modeling procedure}

In an ideal analysis of a double-exposure hologram, the observed fringe pattern is inverted to determine the 3-D displacement vector $\mathbf{L}$ for a given point $\mathbf{P}$ on the borehole wall. Rigorous methods require at least three observations of $\mathbf{L}$, either from multiple holograms (Ennos, 1968) or from several points on one large hologram (Dhir and Sikora, 1972). Our experiments are conducted within the confines of a borehole; the production of multiple or large holograms to determine the borehole wall displacement field is difficult or impossible. Instead, the desired parameters (elastic moduli) are determined directly by spatially modeling the observed holographic fringe patterns.

The first step of the modeling algorithm selects a grid of borehole wall object points $\left(P_{i j}\right)$ with positions relative to an instrument Cartesian $(x, y, z)$ coordinate system (Figure 3). Note that the $x-z$ plane through the origin includes the source point (S) and is perpendicular to the borehole axis. The $x-y$ plane and the $y$ axis are tangent to the borehole wall and parallel to the borehole axis. For each point $P_{i j}$, a displacement vector $\mathbf{L}_{i j}$ is found by

$$
\mathbf{L}_{i j}=\mathbf{T}+\mathbf{I}_{i j}
$$

where $\mathbf{T}$ is the optics module translational displacement vector (constant for all $P_{i j}$ ) and $\mathbf{I}_{i j}$ is the induced normal force displacement vector (dependent upon $P_{i j}$ ) discussed in more detail below. The component of the sensitivity vector $\mathbf{K}_{i j}$ for the raypath $S-P_{i j}-H$ is then calculated and combined with $\mathbf{L}_{i j}$ via equation (4) to find the phase difference $\delta_{i j}$.

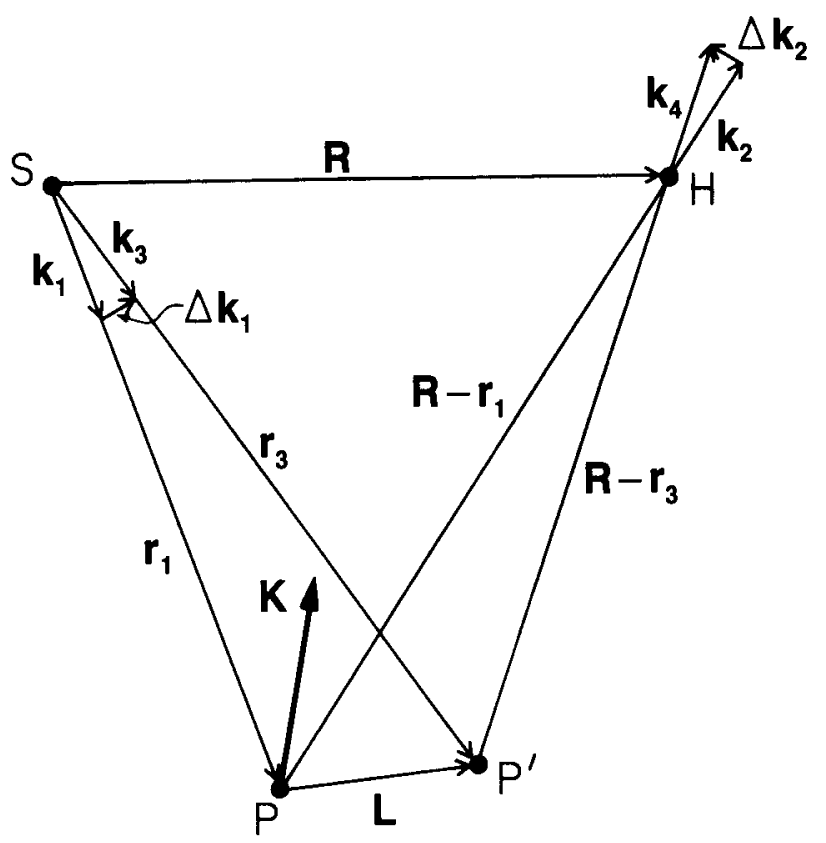

FIG. 2. Raypath diagram illustrating double-exposure process. Object beam laser light propagates from the source point (S) to a point $(P)$ on the borehole wall and is reflected to a point on the holographic emulsion $(\mathrm{H})$ for the first exposure. The point $P$ is displaced to $\mathbf{P}^{\prime}$ and the second exposure with the new raypath $\mathrm{S}-\mathrm{P}^{\prime}-\mathrm{H}$ is taken. A dark fringe is produced when the light beams propagating along the two raypaths destructively interfere. $\mathbf{K}=\mathbf{k}_{2}-\mathbf{k}_{1}$ is the sensitivity vector.

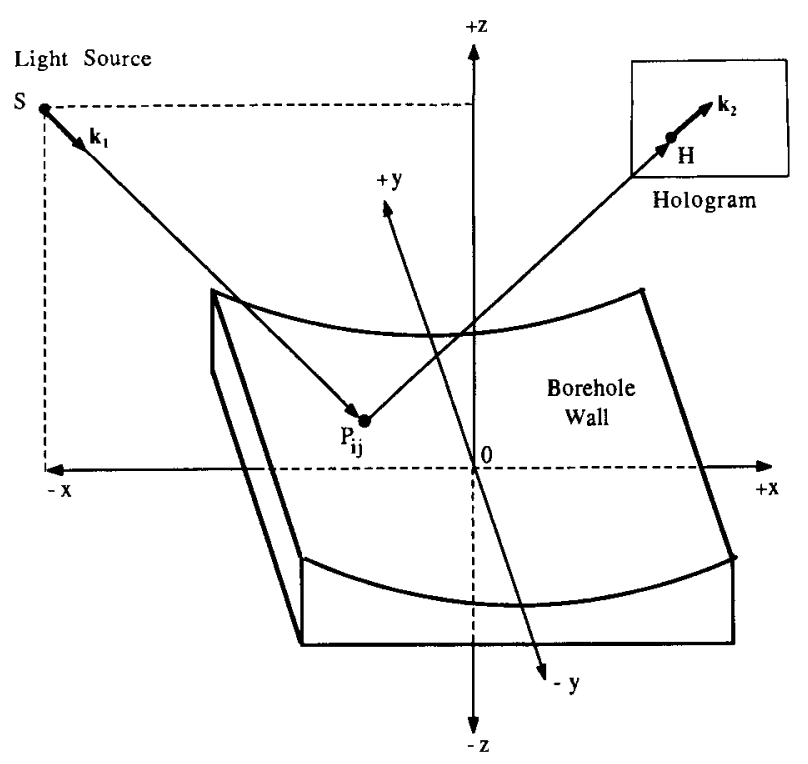

FIG. 3. $(x, y, z)$ coordinate system with origin $\mathrm{O}$ relative to the borehole wall and source point $S$ and hologram point $H$ for purposes of calculating a fringe pattern. $P_{i j}$ is a grid point. 
To approximate the width of the dark fringes in the photographs, the algorithm determines a dark fringe and posts a black mark at $P_{i j}$ in the calculated fringe pattern if $\delta_{i j}$ corresponds closely to an odd number of half-wavelengths of laser light; i.e.,

$$
\left|\delta_{i j}-2 \pi\left(M+\frac{1}{2}\right)\right|<0.15,
$$

where $M$ is any integer and the value 0.15 is an empirically determined constant. Future work will use digital image processing techniques for more precise fringe positioning. Nothing is plotted if a dark fringe is not declared.

Inputs to the algorithm are of two types: those premeasured and initialized during the forward modeling procedure (source position $\mathrm{S}$; hologram position $\mathrm{H}$; and applied force, $\mathrm{F}$ ) and those varied in order to be determined (Young's modulus $E$; Poisson's ratio $v$; and translational displacements $\mathbf{T}$ ).

\section{Normal force displacement model}

To find the induced displacements $\mathbf{I}_{i j}$, the fringe modeling algorithm relies upon the theory of surface displacements on an isotropic elastic half-space subjected to a normal point load (the Boussinesq problem) given by (Timoshenko and Goodier, 1970)

$$
U_{\zeta}=\frac{F(1-v)}{\pi E_{\rho}}
$$

and

$$
U_{\mathrm{p}}=\frac{-F(1-2 v)(1+v)}{2 \pi E_{\rho}},
$$

where $U_{\xi}$ is the displacement normal to the surface, $U_{p}$ is the radial displacement from the point of indention, $F$ is the applied normal force, $\rho$ is the radial distance from the point of indention, $E$ is Young's modulus, and $v$ is Poisson's ratio. The relationship of the cylindrical $(\rho, \phi, \zeta)$ coordinate system with origin $\mathrm{O}^{\prime}$ at the point of force application to the Cartesian $(x, y, z)$ coordinate system described above is illustrated in Figure 4. Anisotropy has not been considered in this study. For rock, $E$ commonly ranges from 10 to $100 \mathrm{GPa}$; forces of 50 to $5000 \mathrm{~N}$ are required to achieve sufficient displacements $(0.5$ to $5 \mu \mathrm{m})$ for holographic measurement. Typical displacements (Figure 5) are plotted for a normal force of $5000 \mathrm{~N}$ on an elastic half-space with $E=50 \mathrm{GPa}$ and $v=0.3$.

The Boussinesq solution is an approximation to the true response of the material to the force; for example, the displacement equations (7) and (8) are singular at the point of force application. In reality, a finite area exists at the indenterrock contact in which nonelastic processes (plastic deformation and fracturing) may dominate the induced displacements, making a distributed load solution more appropriate. The steel indenter typically leaves marks on the borehole wall which are less than $1 \mathrm{~mm}$ in diameter, providing a conservative estimate of the area of contact. A comparison of the solutions for a point and for a circularly distributed load (Timoshenko and Goodier, 1970) using the parameters of Figure 5 indicates rapid convergence past $0.2 \mathrm{~cm}$ from the point of force application; i.e., the distributed load values fall within the thickness of the lines drawn for the point load. The region less than $0.5 \mathrm{~cm}$ from the force application point is blocked by

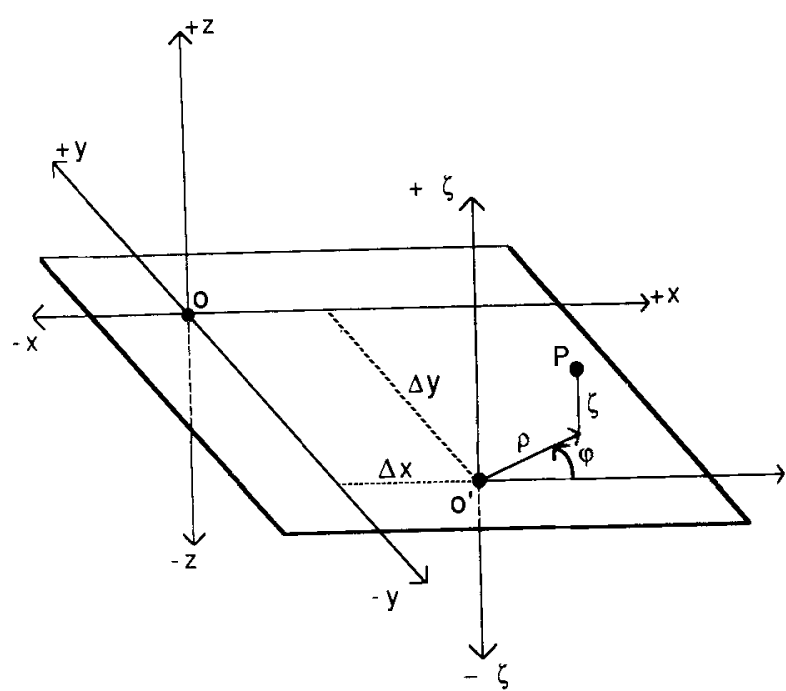

Fig. 4. Relationship of cylindrical $(\rho, \phi, \zeta)$ induced displacement coordinate system to hologram Cartesian $(x, y, z)$ coordinate system. Normal force is applied at origin $\mathbf{O}^{\prime}$, and origins are separated by distances $\Delta x, \Delta y$. $\mathrm{P}$, a point on the borehole wall, has cylindrical coordinates $(\rho, \phi, \zeta)$.

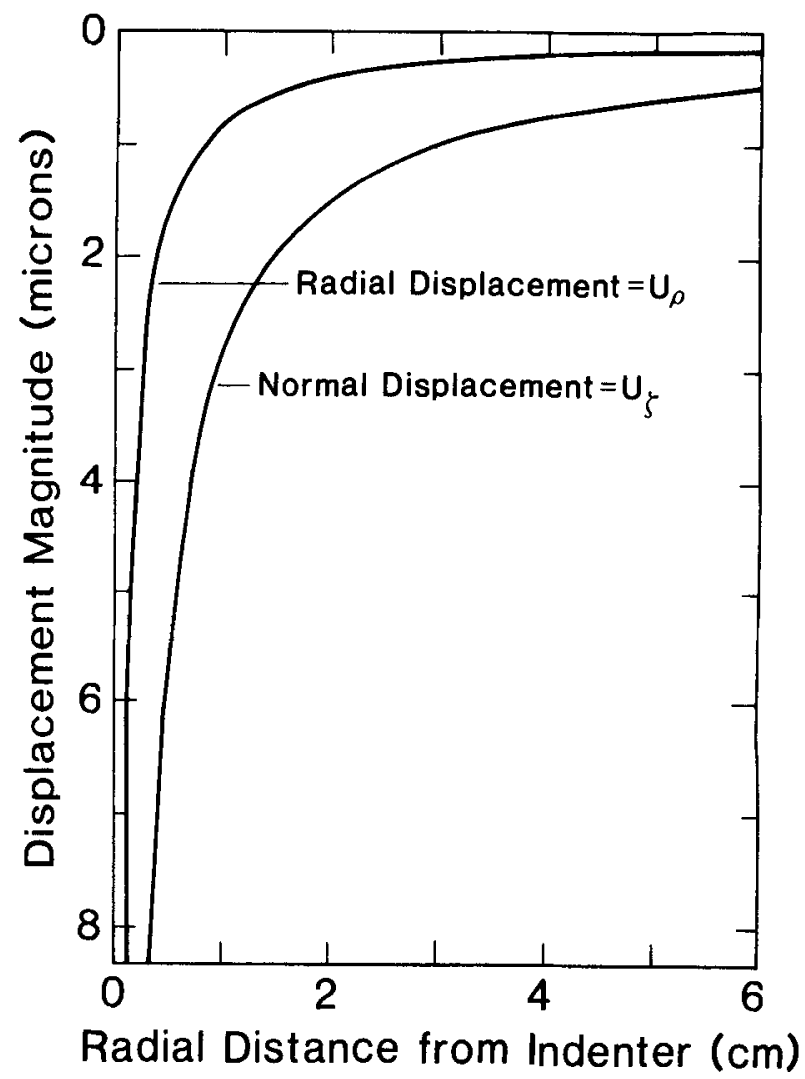

Fic. 5. Typical surface displacements due to a normal force of $5000 \mathrm{~N}$ on an elastic material. 
the steel indenter in the reconstructed holographic image: therefore use of equations (7) and (8) is justified.

Because our instrument requires a $30.5 \mathrm{~cm}$ diameter borehole, curvature over the $10 \mathrm{~cm}$ wide hologram viewing area is minimal, and the flat-surface Boussinesq solution is applicable. Adjustments to these solutions will be necessary in smaller boreholes however. Additionally, the instrument is constructed for use in boreholes of circular cross-section; deployment in boreholes which have become irregular due to washouts, breakouts, or drilling-induced ellipticity would result in deviation from normal of the applied force direction. Nonnormal forces may be accounted for by separating the applied force into components normal and parallel to the surface, whereupon the above Boussinesq and the Cerruti (Fung, 1965) solutions may be superposed.

In principle, both $E$ and $v$ may be found with the holographic technique. In practice, however, the force-induced displacements are only weakly dependent upon the value of $v$. The number and size of the fringes are strongly controlled by the magnitude of $E$ (Figure 6a), whereas variations in $v$ over the range commonly encountered in rocks $(0.25$ to 0.35$)$ produce minimal change in the fringe patterns (Figure 6b). This is quantitatively illustrated in Figure 7 where distances of the zeroth and first-order fringes to the point of force application, determined by modeling the fringe patterns, are plotted. A zeroth-order fringe is formed when the phase difference $\delta$ corresponds to one half-wavelength $\lambda$. In Figure 7 a the $F / E$ ratio is held constant and $v$ is the independent variable, whereas in

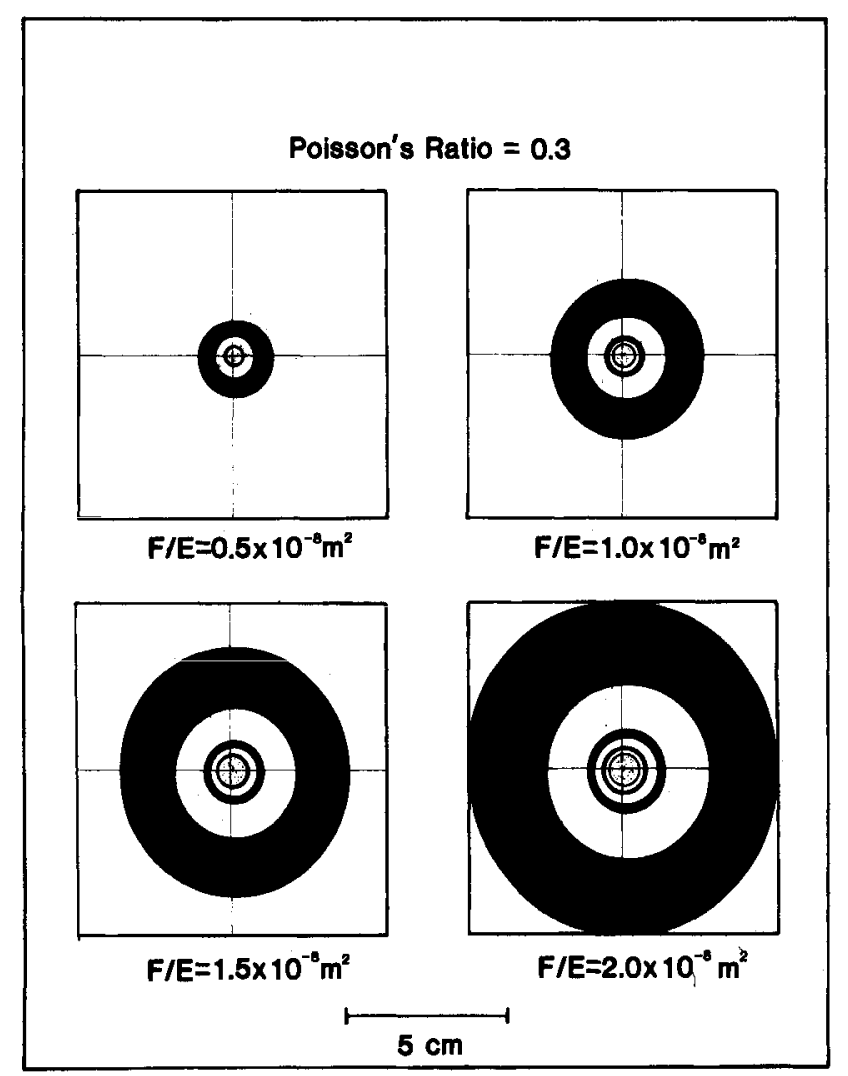

(a)
Figure $7 \mathrm{~b} v$ is held constant and $F / E$ is varied. Although the positions of the fringes are affected by both $E$ and $v$, the effect of $E$ is much larger; i.e., small changes in $E$ produce fringe position shifts larger than those due to extreme changes in $v$.

Away from the point of force application, reconstructed holographic inage fringes have finite width $(\sim 1 \mathrm{~cm})$ for the zeroth-order fringe with poorly defined edges, making impossible accurate determination of the fringe center by visual observation. Our fringe pattern modeling is unable to resolve differences due to small changes in $v$; the technique is applied to determine $E$ only for an assumed value of $v$. This introduces a small error in determined values of $E$; however, this error is insignificant when compared to the fringe pattern matching uncertainty discussed below.

\section{METHODS}

\section{Field experiments}

In the prototype borehole instrument, stability is a critical consideration (Bass et al., 1986). Additional rigid body displacement fringes are produced in the final image by movement of the optics between holographic exposures. The instrument is composed of two separate modules in which force application and optics are mechanically separated to minimize this problem.

The force module applies normal forces up to $1200 \mathrm{~N}$ to the borehole wall. Force is supplied by two pistons (Bimba Co.

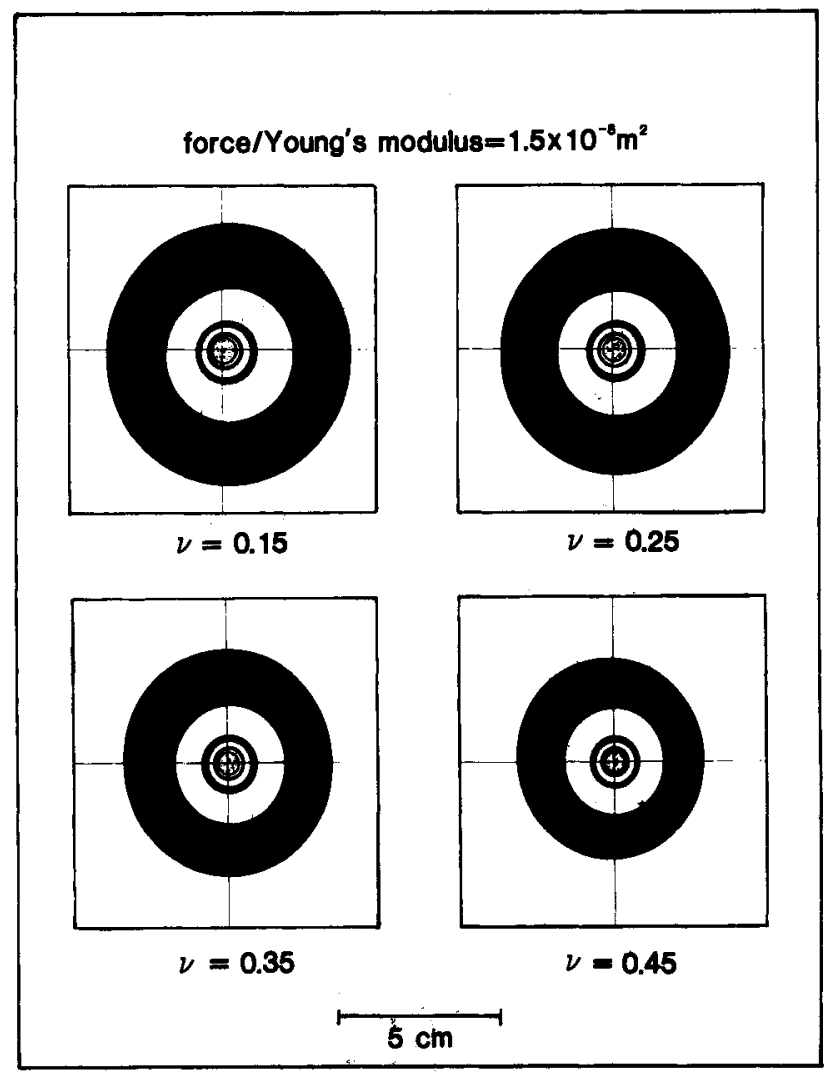

(b)

FIG. 6. (a) Sensitivity of the Boussinesq holographic fringe pattern to variations in the modulus of elasticity $E$. $F$ is the applied normal force. (b) Sensitivity of the Boussinesq holographic fringe pattern to variations in Poisson's ratio $v$. 
(a)

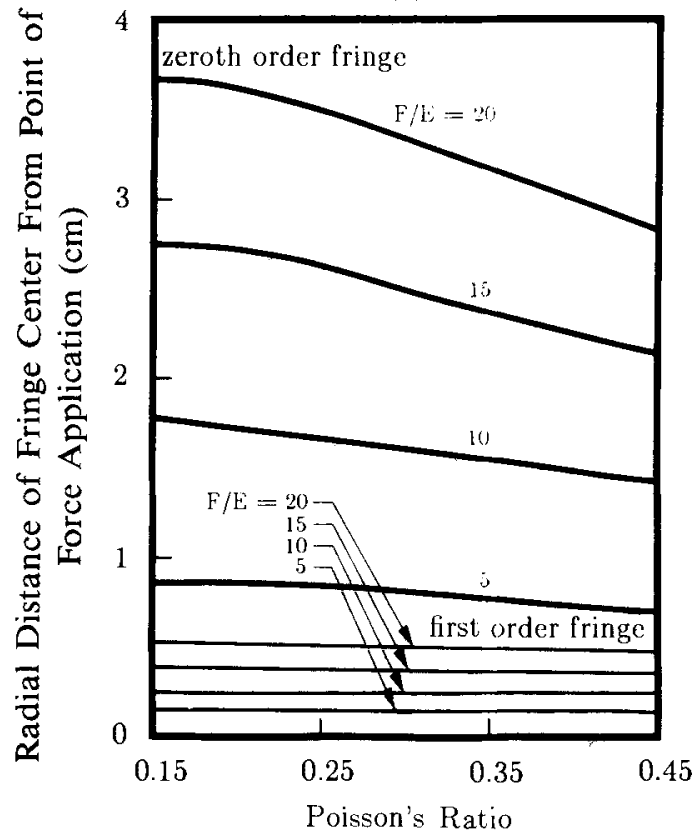

(b)

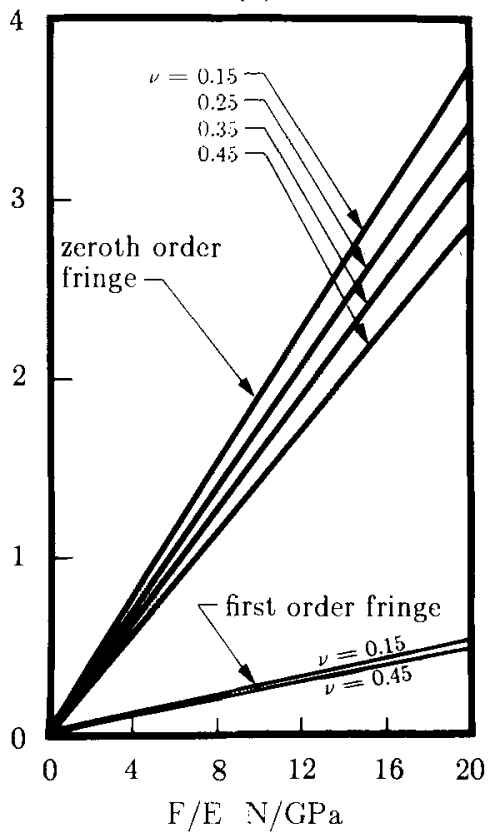

FIG. 7. Distance of zeroth-and first-order fringes from point of force application. (a) Distance of fringe center versus Poisson's ratio v. (b) Position of fringe center versus force/elastic modulus ratio $F / E$.

\# FO-31-1.5) and transmitted to the rock by a steel indenter arm. During the experiment, the force is applied after the first exposure and maintained during the second exposure (Figure 1). Conversely, the force may be applied for the first exposure and removed during the second. The magnitude of the applied force is indicated by the piston air pressure and is also dependent upon the azimuth at which the experiment is conducted within a horizontal borehole. The applied force was calibrated to measured air pressures and borehole azimuth by a load celi placed in the port of a mock borehole in the laboratory (Schmitt, 1987); uncertainty of the applied force as determined from the measured air pressures was less than 10 percent.

The second module contains a He-Ne laser $(638.2 \mathrm{~nm}$ wavelength), holographic film, and the optics required to create an off-axis hologram. Translational motions of this module between holographic exposures greater than $\sim 300 \mathrm{~nm}$ result in additional fringes in the holographic image. Motions larger than $5 \mu \mathrm{m}$ produce high fringe densities which make fringe interpretation difficult. To maintain a high degree of stability. both modules are individually locked into place in the borehole by pneumatic pistons.

\section{Laboratory experiments}

Experiments were conducted in the laboratory to evaluate the applicability of the method and to gain data analysis experience. Calibrated normal forces from 50 to $2000 \mathrm{~N}$ were applied to aluminum and brass blocks $(2.54 \mathrm{~cm}$ thick, $25.4 \mathrm{~cm}$ square). In these bench tests, the indenter was a specially built steel lever with adjustable mechanical advantages of $0.5,1.0$, and 2.0, which magnified the force supplied at one end by a compressed air piston (Bimba \#FO-125-4-EE2) (Schmitt,
1987). The optics module was placed over, but not in contact with, the apparatus in order to make holographic exposures for the tests. Force magnitudes during a test were monitored by strain gauges (Measurements Group, \#CEA-06$500 \mathrm{UW}-350$ ) whose responses had been calibrated against a hydraulic load cell (Enerpac LC-102) to an accuracy of better than 2 percent.

\section{RESUITS AND DISCUSSION}

\section{Laboratory calibrations on metals}

Young's modulus measurement tests were conducted on aluminum (alloy 2024. 3.8-4.9 percent $\mathrm{Cu}, 0.3-0.9$ percent $\mathrm{Mn}$, 1.21 .8 percent $\mathrm{Mg}$ ) (Figure 8, Table 1) with applied forces from 525 to $1989 \mathrm{~N}$. These holograms are of particular interest in that the larger applied forces produced sizable translations, which are evidenced by the long subhorizontal parallel fringes across the photographs. Despite the addition of these additional fringes to the hologram, the modulus of elasticity of the aluminum block was found to be $70 \pm 5 \mathrm{GPa}$, in close agreement with the published value of $73.1 \mathrm{GPa}$ for an aluminum alloy with similar composition (Gray, 1963). Unexpectedly, the translational fringes allow a greater confidence in the result due to the fact that if these fringes are readily observable (as in the last three photographs of Figure 8), they may be easily modeled and accounted for to yield directly the dark fringe order. Similar experiments on yellow brass (ASTM B 171, alloy \# 365) gave a Young's modulus of $100 \pm 10 \mathrm{GPa}$, near a published value of 103 GPa (Gray, 1963). Better constraint on the translational displacement vector $T$ explains the 


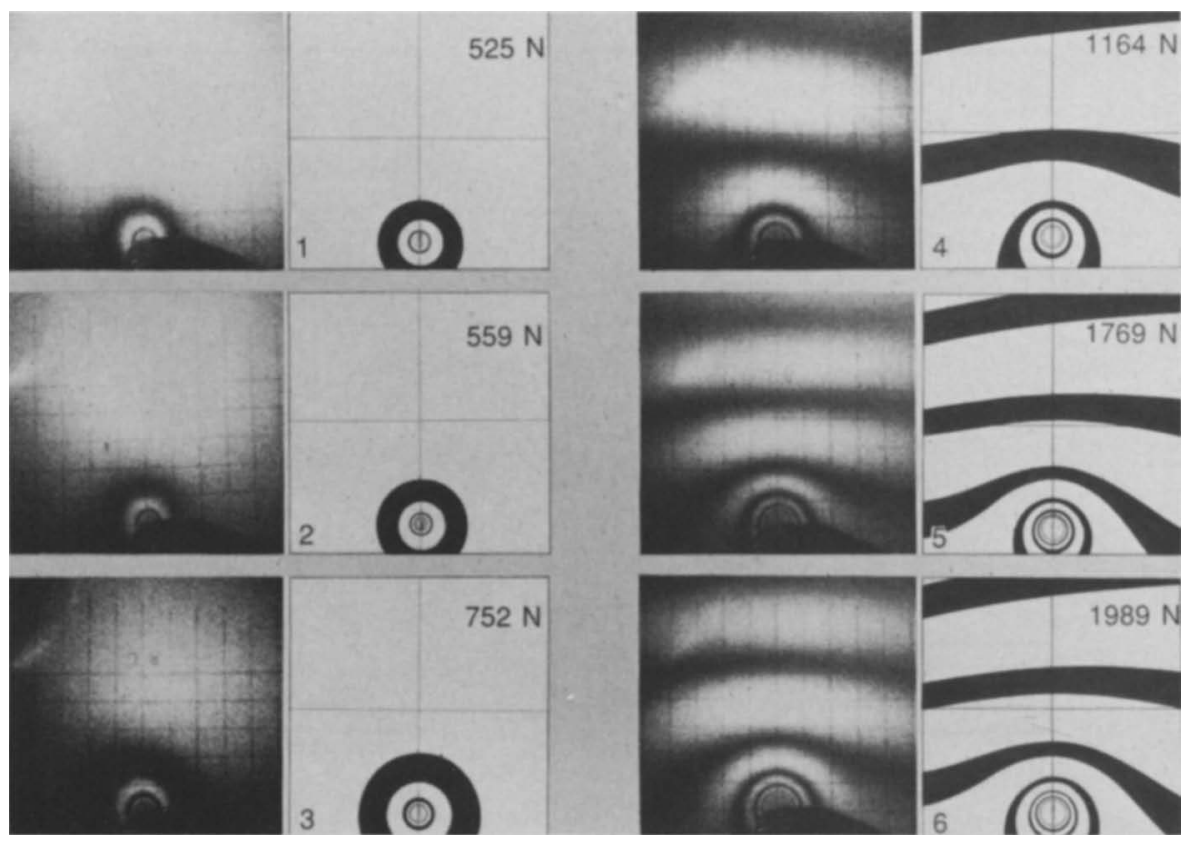

FIG. 8. Laboratory observed and corresponding calculated synthetic fringe patterns for elastic modulus experiments in aluminum. Circular fringes are due to displacements by a known point force. Translational fringes run across the last three images. The applied normal force for each case is given in the upper right-hand corner of the synthetic fringe patterns.

lower uncertainty in the value of Young's modulus for the aluminum experiments.

Individual uncertainties for each fringe pattern are determined from the range of $E$ encountered in a series of calculated fringe patterns which best match those observed. The criterion for a best match is that the fringe centers, as determined from the photographs and plotted on a transparent material, lie within the modeled fringe patterns plotted at the same scale as the photograph when overlaid. This method is somewhat qualitative; however, fringes near the point of force application are narrow (approximately $1 \mathrm{~mm}$ in width as discerned by the eye), allowing precise spatial comparisons. The laboratory and field uncertainties are not statistical but represent the range from the maximum to the minimum possible $E$ for an entire series of holograms as, for example, those for the aluminum block in Figure 8.

\section{Laboratory results on rock}

Laboratory holographic experiments were also conducted on a block of dolomitic marlstone taken from the same mine in which earlier tests (Bass et al., 1986; Schmitt et al,, 1986) and field experiments described below were carried out. The rock is a keragenaceous dolomitic marlstone (oil shale); the rock density of our sample was measured to range from $2.24 \pm 0.01 \mathrm{~g} / \mathrm{cm}^{3}$ to $2.31 \pm 0.01 \mathrm{~g} / \mathrm{cm}^{3}$ in three cores taken with axes perpendicular to the bedding plane of the rock. Reported porosities of the rock are less than 2 percent as

Table 1. Laboratory calibration on aluminum.

\begin{tabular}{|c|c|c|c|c|c|c|c|c|}
\hline \multirow{2}{*}{$\begin{array}{c}\text { Test } \\
\text { number }\end{array}$} & \multicolumn{3}{|c|}{$\begin{array}{l}\text { Hologram } \\
\text { coordinates } \\
\text { (cm) }\end{array}$} & \multirow{2}{*}{$\begin{array}{l}\text { Applied } \\
\text { force } \\
(\mathrm{N})\end{array}$} & \multicolumn{3}{|c|}{$\begin{array}{c}\text { Translations } \\
(\mu \mathrm{m})\end{array}$} & \multirow{2}{*}{$\begin{array}{l}\text { Elastic } \\
\text { modulus } \\
(\mathrm{GPa})\end{array}$} \\
\hline & $x$ & $y$ & $z$ & & $x$ & $y$ & $z$ & \\
\hline 1 & 0.075 & 5.500 & 18.56 & 525 & 0.000 & 0.000 & 0.000 & $67.5 \pm 2.5$ \\
\hline 2 & 0.900 & 5.400 & 18.56 & 559 & 0.000 & 0.000 & 0.000 & $70 \pm 5$ \\
\hline 3 & 0.075 & 5.550 & 18.56 & 752 & 0.000 & 0.000 & 0.000 & $70 \pm 5$ \\
\hline 4 & 3.175 & 4.700 & 18.56 & 1164 & 0.000 & 0.700 & -0.080 & $70 \pm 5$ \\
\hline 5 & 2.275 & 5.500 & 18.56 & 1769 & 0.000 & 1.000 & -0.060 & $70 \pm 5$ \\
\hline 6 & 1.900 & 5.500 & 18.56 & 1989 & 0.000 & 1.000 & -0.080 & $70 \pm 5$ \\
\hline
\end{tabular}

Note: force application point: $x=0.00, y=-3.75 \mathrm{~cm}, z=0.00$.

Source coordinates: $x=-6.19 \mathrm{~cm}, y=0.00, z=8.20 \mathrm{~cm}$. 
Table 2. Borehole field measurements of elastic modulus.

\begin{tabular}{|c|c|c|c|c|c|c|c|c|c|c|c|c|}
\hline \multirow{2}{*}{$\begin{array}{l}\text { Applied } \\
\text { force } \\
(\mathrm{N})\end{array}$} & \multicolumn{3}{|c|}{$\begin{array}{c}\text { Translations } \\
(\mu \mathrm{m})\end{array}$} & \multirow{2}{*}{$\begin{array}{c}\text { Elastic } \\
\text { modulus } \\
(\mathrm{GPa})\end{array}$} & \multirow{2}{*}{$\begin{array}{c}\text { Test } \\
\text { number }\end{array}$} & \multirow{2}{*}{$\begin{array}{l}\text { Depth } \\
(\mathrm{m})\end{array}$} & \multirow{2}{*}{$\begin{array}{l}\text { Azimuth } \\
\text { (degrees) }\end{array}$} & \multicolumn{3}{|c|}{$\begin{array}{l}\text { Hologram } \\
\text { coordinates } \\
\quad(\mathrm{cm})\end{array}$} & \multicolumn{2}{|c|}{$\begin{array}{l}\text { Force } \\
\text { position } \\
\text { (cm) }\end{array}$} \\
\hline & $x$ & $y$ & $z$ & & & & & $x$ & $y$ & $z$ & $\Delta x$ & $\Delta y$ \\
\hline 197 & -0.100 & 0.850 & -0.055 & $30.5 \pm 2.5$ & $3-5$ & 3.25 & 90 & 1.200 & 2.800 & 18.90 & 0.50 & -2.75 \\
\hline 440 & 0.000 & 1.500 & 1.800 & $35.0 \pm 2.5$ & $3-7$ & 3.25 & 90 & -0.825 & 4.300 & 18.90 & 0.60 & -2.40 \\
\hline 752 & 0.000 & 3.400 & 3.415 & $36.0 \pm 3.0$ & $3-8$ & 3.25 & 90 & 0.500 & 3.300 & 18.90 & 0.65 & -2.55 \\
\hline 207 & -0.700 & 1.200 & 0.000 & $27.0 \pm 1.0$ & $8-1$ & 2.20 & 135 & 0.050 & 4.250 & 18.90 & 1.15 & -2.45 \\
\hline 317 & -0.650 & 2.200 & -0.050 & $29.5 \pm 1.5$ & $8-3$ & 2.20 & 135 & 0.000 & 5.050 & 18.90 & 1.00 & -2.55 \\
\hline 146 & -0.500 & 1.000 & 0.700 & $25.3+1.3$ & $8-8$ & 1.63 & 180 & 0.750 & 4.800 & 18.90 & 1.05 & -2.40 \\
\hline 182 & -2.100 & -0.500 & -0.010 & $26.0+1.5$ & $8-5$ & 1.63 & 180 & 0.400 & 3.150 & 18.90 & 0.80 & -2.55 \\
\hline 232 & -1.250 & 0.040 & 0.000 & $28.0+1.5$ & $8-6$ & 1.63 & 180 & 0.750 & 4.450 & 18.90 & 0.80 & -2.40 \\
\hline 319 & -0.070 & 1.300 & 0.000 & $28.3 \mp 1.3$ & $8-7$ & 1.63 & 180 & 0.900 & 4.450 & 18.90 & 0.85 & -2.50 \\
\hline 186 & -0.200 & 0.550 & 0.000 & $34.0+2.0$ & $8-9$ & 1.63 & 135 & 0.700 & 4.800 & 18.90 & 0.50 & -2.40 \\
\hline 136 & -0.160 & 0.700 & 0.000 & $34.0 \pm 2.0$ & $8-10$ & 1.63 & 135 & -1.050 & 3.200 & 18.90 & 0.55 & -2.60 \\
\hline 327 & -0.300 & 1.100 & -0.040 & $34.0 \pm 2.0$ & $8-11$ & 1.63 & 135 & 1.450 & 3.200 & 18.90 & 0.70 & -2.60 \\
\hline
\end{tabular}

Source coordinates: $x=-6.19 \mathrm{~cm}, y=0.00, z=8.50 \mathrm{~cm}$.

Vertical component of force position is $z=0.00$ for all experiments.

found by comparison of wet and dry sample weights (Blair, 1955). Measured ultrasonic ( $1 \mathrm{MHz}$ ) compressional-wave velocities $\left(V_{p}\right)$ from $3.08 \pm 0.05$ to $3.20 \pm 0.04 \mathrm{~km} / \mathrm{s}$, together with the densities $d$ and assumed values of $v$, were used in the formula

$$
E_{D}=\frac{V_{p}^{2} d(1-v)}{(1+v)(1-2 v)},
$$

to yield dynamic modulus of elasticity $E_{D}$ values for the rock of 13.5 to $19.1 \mathrm{GPa}$. The holographic technique determines static compressional values.

In the holographic test, normal forces from 79.8 to $455 \mathrm{~N}$ were applied perpendicular to the bedding plane. Good matches between the observed and calculated synthetic fringe patterns, similar to those of Figure 8 , yielded an $E$ of $16.8 \pm 2.8 \mathrm{GPa}$. The holographically determined $E$ is in excellent agreement with a value of $17.2 \pm 2.0 \mathrm{GPa}$ for a static compressive $E$ predicted on the basis of the density of our ultrasonically tested samples (Blair, 1955).

The ratio of the static to the dynamic Young's modulus $\left(E / E_{D}\right)$ for a Colorado oil shale is reported to be $\sim 0.7$ and to decrease slightly with increasing confining pressure to 220 MPa (Cheng and Johnston, 1981). This is anomalous behavior since, for most rocks, the ratio approaches unity with increasing pressure due to closing of microcracks within the rock mass. Although lack of knowledge of $v$ precludes an accurate determination of $E / E_{D}$ in our study, the above data constrain $E / E_{D}$ to $0.88 \pm 0.15$ which is similar to the results of Cheng and Johnston (1981).

\section{Field results}

The elastic modulus measurement experiments were conducted in a $30.5 \mathrm{~cm}$ diameter, north-south, horizontal borehole (Figure 9) drilled into a mine pillar in the Mahogany formation of Garfield County, Colorado. Twelve fringe patterns from four positions within the borehole with a variety of applied forces have been analyzed (Table 2); examples of

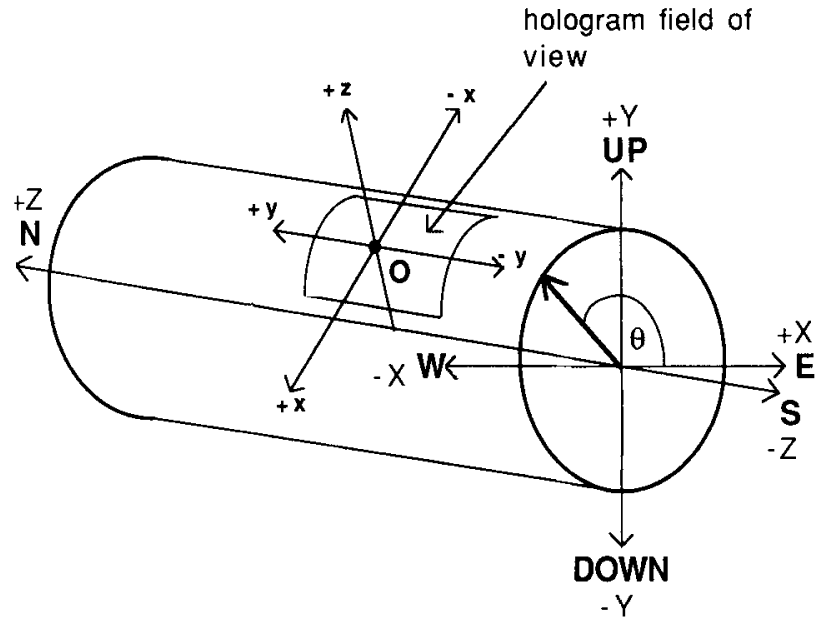

FIG. 9. Relationship of borehole in field experiments to directions north-south ( $Z$ axis), east-west ( $X$ axis), and vertical ( $Y$ axis). Hologram field of view with hologram $(x, y, z)$ coordinate system at azinuth $\theta$.

in-situ data are presented in Figure 10. Although borehole wall shape is accounted for, the calculated fringe patterns are indistinguishable from those calculated for a flat surface due to the small borehole wall curvature, as noted earlier. The in-situ values of $E$, averaged at each of the four test positions within the borehole, ranged from $26.9 \pm 2.9 \mathrm{GPa}$ to $34.0 \pm$ $2.0 \mathrm{GPa}$ with a maximum uncertainty of $\pm 5.8 \mathrm{GPa}$ or approximately 20 percent. An independent measurement of these in-situ values is not available. However, earlier laboratory static compression tests yielded values which range from 8 to $39 \mathrm{GPa}$ (Hatheway and Kiersch, 1982).

Although the present data volume is small and the variations of Young's modulus may be explained by local heterogeneity within the rock mass, a dependence of $E$ on azimuth (0) within the horizontal borehole cannot be precluded. The determined values of $E$ are plotted against borehole azimuth $\theta$ 


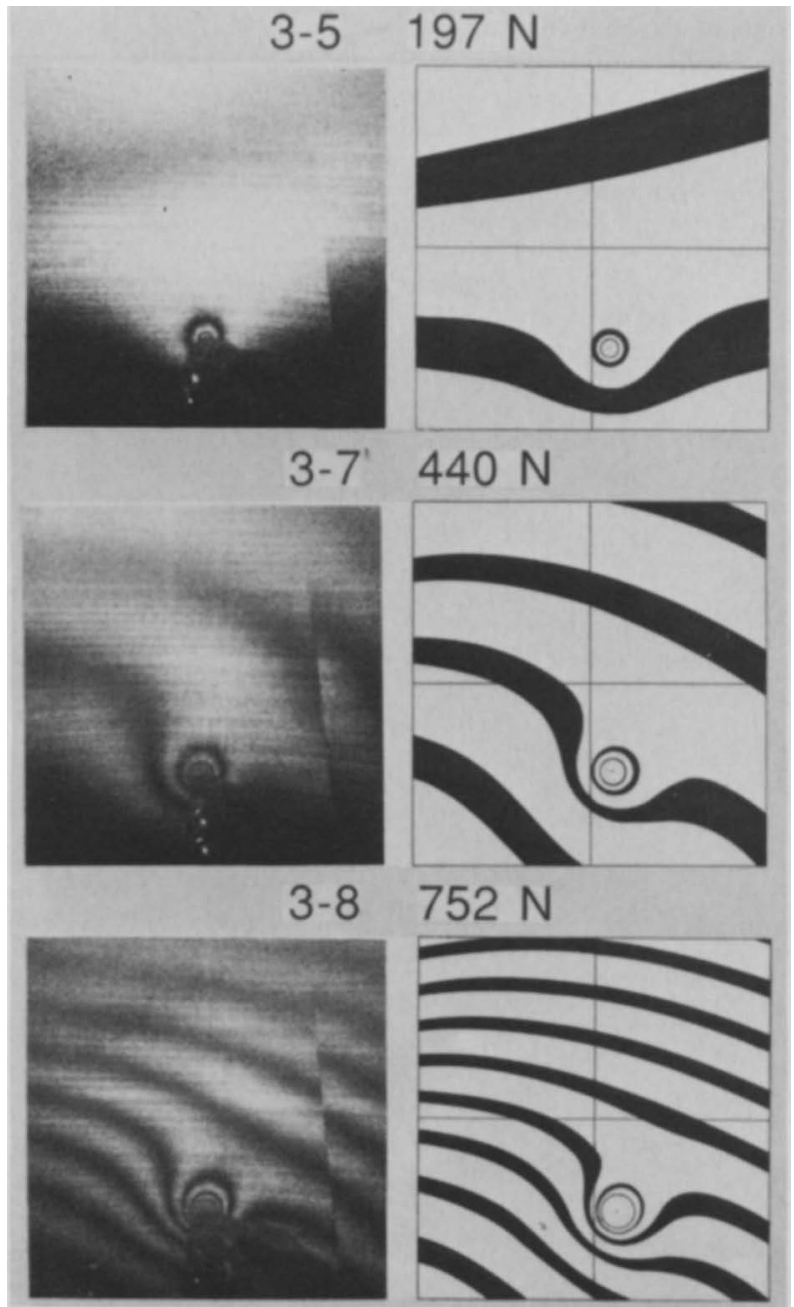

Fig. 10. Field results of elastic modulus experiment in horizontal borehole in mine pillar. Existence of crack seen in discontinuous fringe pattern. Experiment at depth of $3.25 \mathrm{~m}$ and azimuth $\theta$ of $90^{\circ}$ from a horizontal vector pointing east (Figure 9). 3-5, 3-7, and 3-8 are test numbers; normal applied forces are $197 \mathrm{~N}, 440 \mathrm{~N}$, and $752 \mathrm{~N}$, respectively.

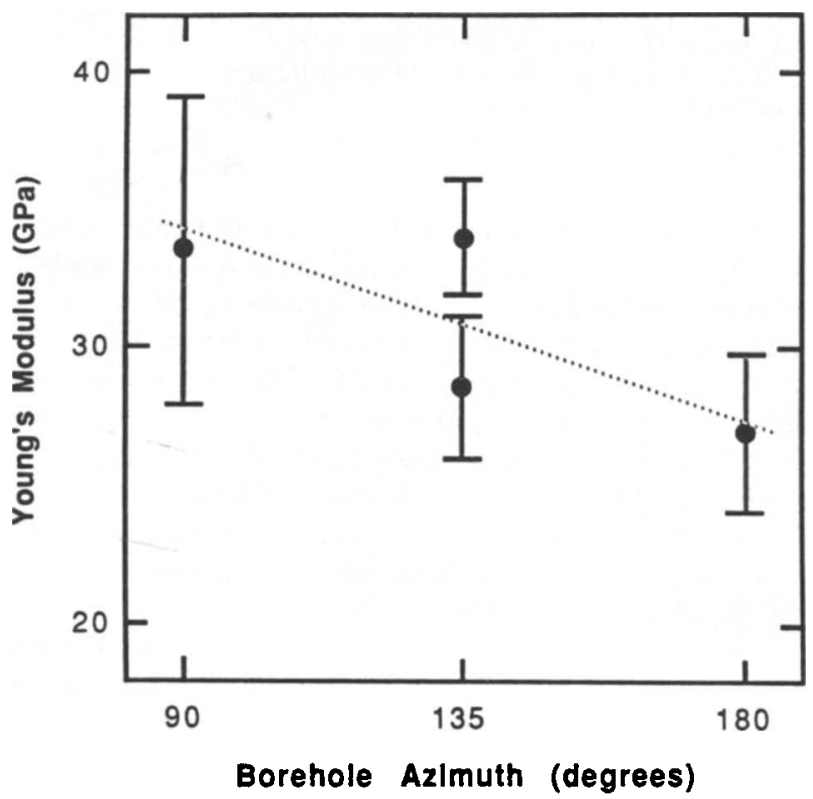

Fig. 11. Dependence of $E$ on borehole azimuth $\theta$. in Figure 11. Although a linear relationship of $E$ to $\theta$ is not suggested, a straight line fitted to the data to illustrate the dependence of $E$ on $\theta$ yields

$$
E(\theta)=(41.1 \pm 7.7 \mathrm{GPa})-\left(0.077 \pm 0.032 \frac{\mathrm{GPa}}{\text { degree }}\right) \theta
$$

where the uncertainties are determined from the extreme values. Equation (10) and its maximum and minimum values (plotted as a dotted line in Figure 11) suggest that the rock is less compressible normal to the bedding planes than parallel to them, in contrast to laboratory measurements in a calcareous, dolomitic marlstone of low kerogen content which give $41.0 \mathrm{GPa}$ parallel to and $25.2 \mathrm{GPa}$ perpendicular to the bedding planes (Blair, 1955). A dependence of $E$ on $\theta$ is not unexpected, since the rock is visually anisotropic with well defined bedding planes.

Evidence for a small crack in the borehole wall (Figure 10) is given by discontinuous fringes in the hologram photographs which indicate a disruption of the borehole wall displacement field, but borehole televiewer logging did not find any cracks at this position. Although the applied force activates motion across the crack, it is sufficiently removed from the force application point to have little impact upon the induced Boussinesq displacements. These holograms point out an important advantage of the optical holographic technique over more conventional methods: the entire displacement field is recorded and data quality is easily assesed by inspection of the holographic image. Defects in the rock mass may not be as readily apparent in methods which require the application of strain gauges to the material that could seriously affect results.

\section{CONCLUSION}

(1) Laboratory tests of the holographic Young's modulus measurement by application of known normal forces to well defined metal samples confirmed the validity of the holographic method. Additionally, these tests demonstrated that translational displacements, introduced between holographic exposures and considered as noise, may readily be accounted for.

(2) Laboratory holographic measurements on a sample of oil shale yielded a Young's modulus of $16.8 \pm 2.8 \mathrm{GPa}$ consistent with ultrasonic velocity measurements which gave values for the dynamic Young's modulus of 13.5 to $19.1 \mathrm{GPa}$ for values of Poisson's ratio from 0.35 to 0.25 . An advantage of our technique is the straightforward data quality control obtained by viewing the hologram; discontinuities in rock mass which have the potential of adversely affecting the results are easily seen in the fringe patterns. Field experiments have been conducted with a holographic borehole instrument deployed in a horizontal borehole in a mine pillar in the Mahogany formation of Garfield County, Colorado. Measured values of the in-situ Young's modulus of the borehole wall rock are from $26.9 \pm 2.9 \mathrm{GPa}$ to $34.0 \pm 2.0 \mathrm{GPa}$ with a maximum uncertainty of 20 percent. Localized heterogeneity or elastic anisotropy are possible explanations for these variations.

The prototype instrument (dimensions of $27 \mathrm{~cm}$ diameter, $3.4 \mathrm{~m}$ length, and $100 \mathrm{~kg}$ weight) is too large for use in standard production boreholes. However, a smaller version for use 
in fluid-filled boreholes as small as $15 \mathrm{~cm}$ diameter and to depths of $1 \mathrm{~km}$ is currently being tested.

\section{ACKNOWLEDGMENTS}

The authors wish to thank Tom Nolan, Bridget Jensen, Epaprodito Gelle, Michael Long, William Barber, Wayne Miller, Gunther Haehn, and Dick Wickes for assistance in the field and laboratory. Douglas Schmitt greatly appreciates support from the Alberta Heritage Scholarship Fund from 1984 to 1986 . This research was funded by grants from Schlumberger Technical Corporation, Sun Oil Corporation, and the Department of Energy (DE-FG03-85ER 13422).

Contribution 4523, Division of Geological and Planetary Sciences, California Institute of Technology.

\section{REFERENCES}

Bass, J. D. Schmitt, D. R., and Ahrens. T. J., 1986, Holographic in situ stress measurements: Geophys. J., 85, 13-41.

Bieniawski, Z. T., 1978, Determining rock mass deformability: experience from case histories: Internat. J. Rock Mech. Mining Sci. and Geomech. Abst., 15, 237-247.

Bieniawski, Z. T., and Van Heerden, W. L., 1975, The significance of in situ tests on large rock specimens: Internat. J. Rock Mech. Mining Sci. and Geomech. Abst., 12, 101-113.

Blair, B. E., 1955, Physical properties of mine rocks: part III : U.S. Bur. Mines, Invest. Rep. 5130 U.S. Bur. Mines.

Bock, H., Foruria, V., and Lequerica, R., 1984, A new stress relief concept for in-situ stress measurements in rock and its implementation in two recoverable stressmeters, in Jewell, R. J., Chairman, Geomechanics Interaction: National Conference Publication-Inst. Engineers, Australia, Proc. 4th Australia-New Zealand Conf. on Geomechanics, 498-508.

Cheng, C. H., and Johnston, D. H., 1981, Dynamic and static moduli: Geophys. Res. Lett, 8, 39-42.

Crampin, S., 1978, Seismic-wave propagation through a cracked solid: polarization as a possible dilatancy diagnostic: Geophys. J. 53, $467-496$

Dhir, S. K., and Sikora, J. P., 1972, An improved method for obtain- ing the general displacement field from a holographic interferogram : Exp. Mech.. 12, 323-327.

Ennos. A. E., 1968. Measurements of in-plane surface strain by hologram interferometry: I. Sci. Instrum - Ser II 1, 731-746.

Fung, Y. C.. 1965, Foundations of solid mechanics: Prentice-Hall, lnc. Gray, D. E. 1963, American Institute of Physics Handbook, 2nd ed. McGraw-Hill Book Co.

Hatheway. A. W., and Kiersch, G. A., 1982, Engineering properties of rocks, in Carmichael. R. S., Ed., Handbook of physical properties of rocks, II : CRC Press, Inc.. 289-332

Jaeger, J. C.. 1979. Rock mechanics and engineering. 2nd ed.: Canbridge Univ. Press.

Jaeger, J. C., and Cook, N. G. W., 1979, Fundamentals of rock mechanics: Chapman and Hall.

McGarr. A.. and Gav. N. C.. 1978, State of stress in the Earth's crust: Ann. Rev. Farth Plan. Sci., 6, 405-436.

Meyer. T. O. and McVey, J. R., 1974. NX borehole jack modulus determination in homogeneous, isotropic, elastic materials: Rep. of Invest. 7855, U.S. Bur. Mines.

Nur. A.. 1971. Effects of stress on velocity anisotropy in rocks with cracks: J. Geophys. Res.. 76, 2022-2034.

Richardson. R. M. Solomon, S. C., and Sleep, N. H., 1979, Tectonic stress in the plates: Rev. Geophys. Space Phys., 17, 981-1019.

Schmitt, D. R.. 1987, I. Application of double exposure holography to the measurement of in situ stress and the elastic moduli of rock from boreholes. II. Shock temperature measurements in fused quartz and crystalline $\mathrm{NaCl}$ to $35 \mathrm{GPa}$ : Ph.D. thesis, California Inst. of Tech.

Schmitt, D. R.. Smither. C. L., Ahrens, T. J., and Jensen, B. L., 1986. Borehole in-situ holographic stress and elastic moduli measurements: 56th Ann. Internat. Mtg., Soc. Expl. Geophys., Expanded Abstracts. 912

Smither. (.. Schmitl. D. R., and Ahrens, T. J., 1988, Analysis and modeling of holographic measurements of in situ stress: Internat. $J$ Rock Mech. Min. Sci. and Geomech. Abstr., in press.

Stephansson. O.. 1986. Ed., Rock stress and rock stress measurement: Proc.. Internat. Symp. on Rock Stress and Rock Stress Measurements, Centek

Stesky, R. M.. 1985, Compressional and shear velocities of dry and saturated jointed rock: a laboratory study: Geophys. J., 83, 239262

Thomsen, 1.. 1986. Weak elastic anisotropy: Geophysics, 51, 1954 1966.

Timoshenko. S. P., and Goodier. J. N., 1970, Theory of elasticity, 3rd ed.: McGraw-Hill Book Co.

Vest. C. M. 1979. Holographic interferometry: John Wiley and Sons, Inc: 